\title{
CARACTERIZAÇÃO FÍSICO-QUÍMICA DE NANOEMULSÕES CONTENDO FTALOCIANINA DE ZINCO PARA USO EM TERAPIA FOTODINÂMICA
}

\author{
S. C. LAUERMANN ${ }^{1}$, L. T. BRUSCHI ${ }^{2}$, F. I. ZIEMBOWICZ ${ }^{3}$ e M. A. VILLETTI ${ }^{1}$ \\ ${ }^{1}$ Universidade Federal de Santa Maria, Departamento de Física \\ ${ }^{2}$ Universidade Federal de Santa Maria, Departamento de Engenharia Química \\ ${ }^{3}$ Universidade Federal de Santa Maria, Departamento de Química \\ E-mail para contato: mvilletti@ hotmail.com
}

\begin{abstract}
RESUMO - A terapia fotodinâmica envolve a ativação de compostos fotossensíveis por meio da incidência de uma radiação eletromagnética de comprimento de onda específico, levando à formação de espécies reativas de oxigênio e radicais livres que promovem a destruição dos tecidos alvo. Dentre os fotossensibilizadores utilizados nos tratamentos está a ftalocianina de zinco que possui comportamento hidrofóbico, facilitando sua interação com as células doentes porém dificultando sua administração devido à baixa solubilidade em soluções fisiologicamente compatíveis. Com o intuito de promover a estabilidade dos compostos fotossensíveis, aumentar a capacidade de transpor barreiras biológicas, promover o direcionamento do ativo em locais específicos e liberação com velocidade controlada, é realizado o nanoencapsulamento do fotossensibilizador. Neste sentido, o presente trabalho visa avaliar a influência da nanoencapsulação da ftalocianina de zinco através de nanoemulsões para uso em terapia fotodinâmica.
\end{abstract}

\section{INTRODUÇÃO}

O tratamento fotodinâmico consiste na administração de um composto fotossensível nas células doentes, que após introduzido, será exposto à uma radiação de comprimento de onda específico e assim passará à um estado excitado, essa ativação leva o fotossensibilizador à liberar energia quando voltar ao estado fundamental, possibilitando as moléculas de oxigênio presentes no meio absorverem esta energia. As moléculas de oxigênio que encontravam-se no estado triplete passam, após absorção da energia liberada pelo fotossensibilizador, para um estado singlete, que possui caráter oxidante, contribuindo para a morte celular (Ricci-Junior et al., 2006; Soukos et al., 2011).

Muitos tratamentos de algumas enfermidades como doenças cancerígenas, lesões cutâneas e infecções já empregam a terapia fotodinâmica, que tem se intensificado nos últimos anos devido às vantagens que a mesma apresenta com relação aos tratamentos convencionais. A técnica é minimamente invasiva e não consiste de um procedimento cirúrgico, não apresenta efeitos colaterais como náuseas e vômito e mostra alta seletividade, atacando apenas as células doentes (Ethirajan et al., 2011). 
Para que a terapia fotodinâmica seja satisfatória, o comprimento de onda de ativação do fotossensibilizador deve estar situado dentro da faixa terapêutica, que vai de 600 a $800 \mathrm{~nm}$ (Castano et al., 2004). Valores de comprimento de onda menores de que $600 \mathrm{~nm}$, além de possuírem menor efetividade de penetração tecidual, podem interagir com macromoléculas presentes, como a hemoglobina. Já comprimentos de onda acima de $800 \mathrm{~nm}$ não possuem energia suficiente para a ativação do fotossensibilizador (Deprá et al., 2015; Sibata et al., 2000).

A Ftalocianina de Zinco $(\mathrm{ZnPc})$ é um fotossensibilizador muito utilizado em terapia fotodinâmica pois apresenta alta eficiência citotóxica, devido a geração do oxigênio singleto $\left({ }^{1} \mathrm{O}_{2}\right)$, possui também caráter hidrofóbico, facilitando o encapsulamento em nanoemulsões e também sua interação com as células doentes. (Ethirajan et al., 2011).

Nesse contexto, sistemas nanoestruturados têm se mostrado promissores, pois possuem propriedades que possibilitam uma grande variedade de aplicações terapêuticas, principalmente no desenvolvimento de formulações de fármacos hidrofóbicos com liberação controlada. Os sistemas de liberação controlada ajudam no tratamento de doenças, pois podem direcionar o fármaco até os tecidos doentes e liberar de forma controlada a droga por um período longo de tempo.

\section{MATERIAIS E MÉTODOS}

\subsection{Reagentes}

Os solventes empregados foram acetona e diclorometano, ambos de grau analítico, e as soluções foram preparadas com água ultrapura (Milli-Q ${ }^{\circledR}$ ).

Os reagentes ftalocianina de zinco (97\%), monoestearato de sorbitano (Span 60), polisorbato 80 (Tween 80) foram adquiridos da Sigma Aldrich (São Paulo, Brasil). A mistura de triglicerídeos dos ácidos cáprico e caprílico (TCM) da Delaware foi fornecido pela Tovani Benzaquen Repr. Ltda (São Paulo, Brasil). E a lecitina de soja SOLEC F foi gentilmente cedida pela Solae do Brasil.

\subsection{Preparação das nanoemulsões}

As nanoemulsões foram preparadas por meio do método de emulsificação espontânea (Bouchemala et al., 2004), onde o fármaco lipofílico ( $\mathrm{ZnPc}$ ) é dissolvido em um solvente orgânico (diclorometano) juntamente com o óleo que constitui a fase interna da preparação (TCM) e com um tensoativo lipofílico (Span 60). A fase dispersante é formada por água e adicionada de um segundo tensoativo de natureza hidrofílica (Tween 80). Após, verte-se a fase orgânica sobre a aquosa mediante agitação moderada e o solvente orgânico é retirado por destilação à pressão reduzida. Deste modo, a nanoemulsão foi preparada dissolvendo-se 0,937 $\mathrm{mL}$ de ftalocianina de zinco $\left(100 \mu \mathrm{mol} \mathrm{L} \mathrm{L}^{-1}\right.$ em solução de diclorometano), 191,5 mg do tensoativo Span 60 e $0,825 \mathrm{~mL}$ de TCM em $68 \mathrm{~mL}$ de acetona sob agitação magnética, a 40 ${ }^{\circ} \mathrm{C}$ durante 40 minutos. Em seguida essa solução foi adicionada, sob agitação magnética, à uma segunda solução composta de 191,5 mg de Tween 80 em 134 mL de água ultra pura, e a 
agitação foi mantida por 15 minutos. A mistura final foi então submetida à rotaevaporação (60 rpm e temperatura controlada de $40{ }^{\circ} \mathrm{C}$ ) até atingir-se volume final de $25 \mathrm{~mL}$.

\subsection{Caracterização das nanoemulsões}

A caracterização das nanoemulsões foi realizada através da determinação do raio hidrodinâmico, índice de polidispersão, potencial zeta e pH.

Raio hidrodinâmico: $\mathrm{O}$ raio hidrodinâmico foi avaliado em triplicata, após diluição (1:250) da nanoemulsão em água ultrapura e filtração (NYLON, $0,45 \mu \mathrm{m}$ ). As medidas foram realizadas em ângulo de espalhamento de $90^{\circ}$, com laser He-Ne, e comprimento de onda de $637 \mathrm{~nm}$ (Brookhaven Instruments Corporation BI-200SM).

Índice de polidispersão: Foi medido em triplicata, após diluição (1:500) da nanoemulsão em água ultrapura e filtração (NYLON, $0,45 \mu \mathrm{m}$ ) utilizando o equipamento Nanozetasizer ZS (Nano ZS, Zetasizer Nanoseries, Malvern Instruments, Worcestershire,UK).

Potencial Zeta: $\mathrm{O}$ valor potencial zeta foi determinado pela mobilidade eletroforética das nanoemulsões utilizando o equipamento Nanozetasizer ZS (Nano ZS, Zetasizer Nanoseries, Malvern Instruments, Worcestershire, UK). As medidas foram realizadas em triplicata, após diluição (1:500) da nanoemulsão em $10 \mathrm{~mL}$ de $\mathrm{NaCl}$ e filtração em NYLON, $0,45 \mu \mathrm{m}$.

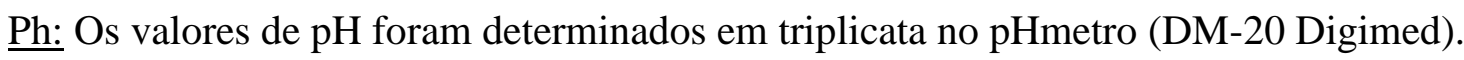

\section{RESULTADOS E DISCUSSÃO}

A nanoemulsão estudada apresentou característica visual homogênea e aspecto opalescente levemente azulado, devido a presença do fotossensibilizador.

A título de ilustração a Figura 1, mostra o gráfico da distribuição do tamanho e a função de correlação da nanoemulsão formada. É possível observar uma distribuição homogênea de tamanho de partículas, com uma população majoritária e outra, com menor significância, resultando um raio hidrodinâmico de $64,8 \mathrm{~nm}$.

Figura 1 - Função de correlação e distribuição do tamanho da nanoemulsão.

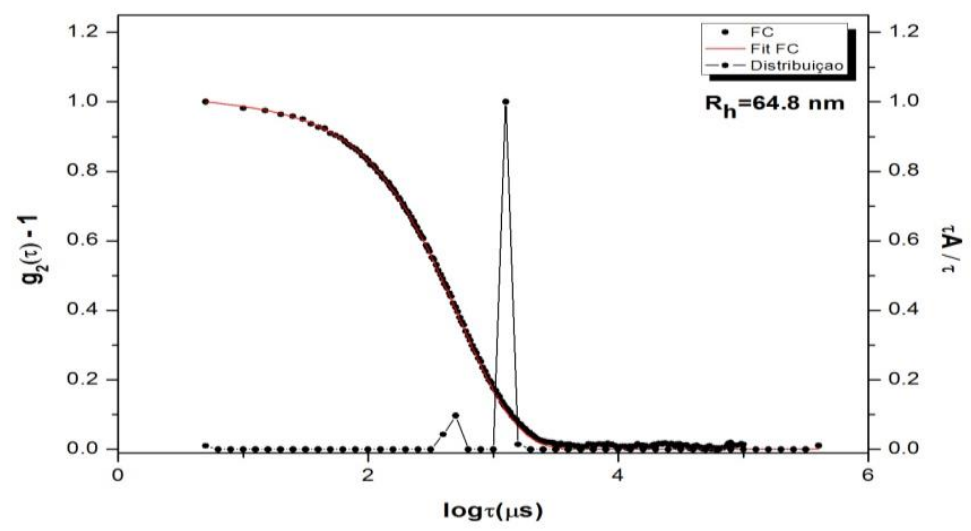


O índice de polidispersão para a nanoemulsão obtido através de técnica de espalhamento de luz foi de 0,282 $\pm 0,049$, considerado baixo $(>0,3)$, o que indica que as nanogotículas apresentaram homogeneidade de tamanho, o que reforça o resultado obtido para a distribuição apresentada na Figura 1.

A análise de microscopia eletrônica de varredura apresentou o tamanho da nanoemulsão semelhante ao resultado do espalhamento de luz que indicou o raio hidrodinâmico, pois analisando a Figura 2 é possível estimar um diâmetro entre 100 e $200 \mathrm{~nm}$.

Figura 2 - Microscopia eletrônica de varredura

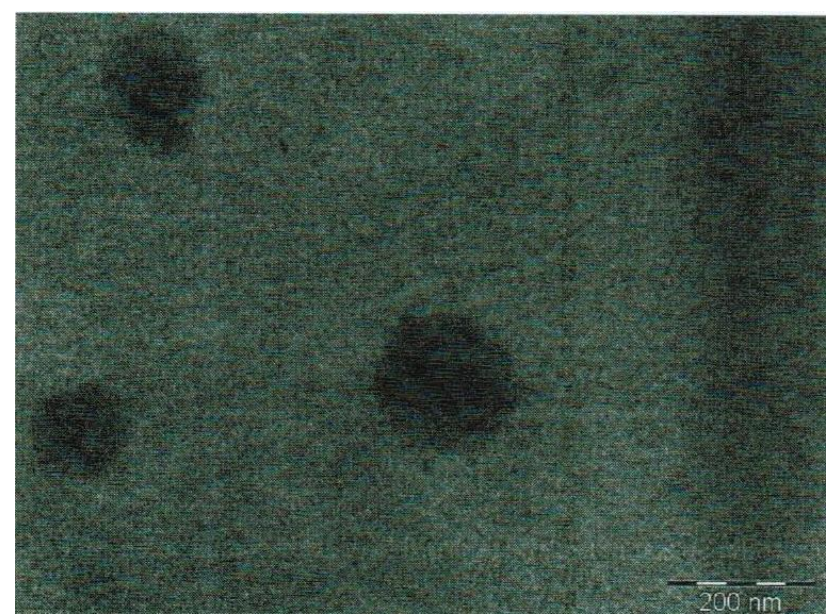

$\mathrm{O}$ pH do meio no qual estão as nanoemulsões é um importante fator para o controle da estabilidade e do tamanho das partículas. $\mathrm{O}$ valor de $\mathrm{pH}$ encontrado foi de 4,62 $\pm 0,03$, estando fora da faixa farmacêutica recomendada para administração injetável.

O potencial elétrico da superfície das partículas é obtido através do potencial zeta. Mudanças na interface como a fase dispersante afetam o potencial zeta, isso se deve a dissociações de grupos funcionais ou adsorção de espécies iônicas no meio aquoso, causados pelos componentes das formulações, como tensoativos e $\mathrm{pH}$. O potencial zeta obtido para a nanoemulsão foi de $-44,3 \pm 0,75$. O elevado valor do potencial zeta em módulo observado indica uma elevada estabilidade da nanoemulsão, devido à alta barreira de energia de repulsão eletrostática entre as nanopartículas, que tendem a evitar possíveis agregações das gotículas.

\section{CONCLUSÃO}

A formulação das nanoemulsões apresentou características físico-químicas adequadas, com tamanho de partícula na escala nanométrica, menor que $100 \mathrm{~nm}$, índice de polidispersão maior que o ideal 0,25 , valores de potencial zeta negativos, contudo o $\mathrm{pH}$ da emulsão não apresentou-se adequado para uso dentro da faixa farmacêutica.

Portanto, os resultados dos estudos confirmam que as nanoemulsões contendo ZnPc preparadas nesse trabalho são sistemas de liberação de fármacos promissores para o emprego em terapia fotodinâmica. 


\section{REFERÊNCIAS}

BOUCHEMALA, K.; BRIANÇONA, S.; PERRIERB, E.; FESSI, H., Nano-emulsion formulation using spontaneous emulsification: solvent oil and surfactant optimization. Int. J. Pharm., v. 280, p. 241-251, 2004.

CASTANO, A. P; DEMIDOVA, T.; HAMBLIM, M. R. Mechanisms in photodynamic therapy: Part three - Photosensitizer pharmacokinetics, biodistribution, tumor localization and modes of tumor destruction. Photodiagnosis Photodyn. Ther., v. 2, p. 91-106, 2005.

DEPRÁ, T. F. L. Nanoencapsulação de ftalocianina de zinco para o uso em terapia fotodinâmica. Dissertação (mestrado em Química), Universidade Federal de Santa Maria, 2006.

ETHIRAJAN, M.; CHEN Y.; JOSHI P.; PANDEY R. K. The role of porphyrin chemistry in tumor imaging and photodynamic therapy. Chem Soc. Rev., v. 40, p. 340-362, 2011.

RICCI-JUNIOR, E.; MARCHETTI, J. M. Zinc (II) phthalocyanine loaded PLGA nanoparticles for photodynamic therapy use. Int. J. Pharm., v.310, p. 187-195, 2006.

SIBATA, C.H.; COLUSSI, V.C.; OLEINICK, N.L.; KINSELLA, T.J. Photodynamic therapy: a new concept in medical treatment. Braz. J. Med. Biol. Res. v. 33, p.869-880, 2000.

SOUKOS, N. S.; GOODON, M. J. Photodynamic therapy in the control of oral biofilms. Periodontol. 2000, v. 55, p. 143-146, 2011. 